\title{
Applications of fungal pigments in biotechnology
}

\author{
Sumbal Sajid ${ }^{1 *}$ and Nukba Akbar ${ }^{2}$ \\ 1. Institute of Biochemistry, University of Balochistan Quetta, 87300-Pakistan \\ 2. Department of Biochemistry Sardar Bahdar Khan Women University, Quetta, 87300- Pakistan \\ *Corresponding author's email: balochsum@gmail.com \\ Citation
}

Sumbal Sajid and Nukba Akbar. Applications of fungal pigments in biotechnology. Pure and Applied Biology. Vol. 7, Issue 3, pp922-930. http://dx.doi.org/10.19045/bspab.2018.700111

\begin{tabular}{llll}
\hline \hline Received: 27/05/2018 & Revised: 06/07/2018 & Accepted: 09/07/2018 & Online First: 10/07/2018 \\
\hline \hline
\end{tabular}

\section{Abstract}

The rapid development is leading the demand of colors in biotechnology related to food, textile, medicine and cosmetics. The health hazards of synthetic colors compel industries to adapt natural pigments. "Among them; microbial pigments most important and very diverse in nature." In this group the fungal pigments are of high demand due to mostly being extracellular metabolites, easy to extract and have enormous biotechnological applications. "Almost all genus of fungi produce efficient amount of pigment which depend and vary from species to species. Yeast, basidiomycetes, Zygomycetes, filamentous fungi, endophytic fungi, marine fungi and halophiles are most important groups which produce useful pigments. The pigments mostly found in kingdom fungi include melanin, phenazines, flavins, carotenoids, violacein, indigo, ankaflavins, canthaxanthin, prodigiosin and moascins. These pigments are being extracted on industrial scale for many biotechnological purposes. This review is intended to highlight the importance of pigments produced by fungi. The research on pigments producing fungi can lead to the development of industries related to textile, food, medicine, and cosmetics.

Keywords: Biotechnology; Cosmetics; Fungi; Food; Medicine; Textile

\section{Introduction}

The chemical compounds which absorb light in the wavelength range of the visible region are known as pigment, which can be natural, synthetic, or inorganic [1, 2]. "Natural pigments are found in all kingdoms of algae, fungi, plants, animals" [3].

All advance animals including human communicate and contact surrounding by the help of pigments that is why they are of high utility for living organisms [3]. The previous studies show that microbes and plants have the ability to produce some natural products, their chemistry and composition depends on the organism excreting it. These kinds of natural products are mostly secondary metabolites. Fungi have the ability to produce different secondary metabolites including cephalosporin, penicillin, statins, ergotrate, pigments and other compounds [4].

Among microbes, fungi have the ability to produce potent pigments which can be used as dye or as a food colorant [5]. A wide range of pigments are produced by fungi, exhibiting many biological properties beside some of being cytotoxic [6]. The studies show that pigment production by filamentous fungi is gaining interest amongst food colorants, textiles and cosmetic industries due to their properties [7]. 


\section{History of pigments}

The art of dyeing and coloring has long history. It has been in use since the Bronze age. The earliest use of natural dyes was first recorded in China dated back 2600 before Christ (BC). In 2500 BC dyeing technology was adopted in Indian Subcontinent, being evident in ruins of Mohenjodaro and Harappa civilization of 3500 BC. Evidence of wrapping mummies in colored cloths has been found in Egypt. Different dyes such as madder, wood, weld, Brazil wood, Dark reddish purple and indigo was known by fourth century anno Domini (AD). Even Brazil has been named by the wood found in there [8]. The art and designing of coloring spread widely with development of civilization [9]. This was main reason for studies on bio-colorant which enhanced due to their multiple functions in daily life [10].

Pigments can be divided into many classes on the basis of their nature such as natural pigments, synthetic pigments and inorganic pigments. Synthetic pigments are sourced by laboratories, inorganic pigments occur naturally in ores and natural pigments are produced by plants, microorganisms, animals and fungi [2].

\section{Microbial pigment}

The natural pigment extracted from microorganisms is termed as microbial pigment. Food and textile colorants are being extracted by bacteria, algae and fungi. These microbes are promising species to produce natural colors [11].

\section{Fungal pigment}

The kingdom fungi are full of diverse and unique group of organisms which produce various kinds of biotechnologically important metabolites. Among fungal species Monascus Purpureus produce variety of secondary metabolites which is usually colored naturally. This fungal species is also called red-purple yeast [12], and is reported to produce red (azaphilones), yellow pigment called ankaflavine and monascine, purple pigment called rubropunctamine, and orange pigment called rubropunctatine and monascorubrine. These pigments have been used from centuries in oriental foods (red mold rice) in Southern China, Japan and Southeast Asia. These pigments are being extracted by Monascus have abundant utilities in food, textile, cosmetics industry and approximately 50 patents have been made by color extract of this particular species [13].

Among all classes of fungi, filamentous fungi produce wide variety of bio-colorants, which include melanins, phenazines, flavins, carotenoids, qunones, violacein, indigo, and monascins [14]. Carotene is most important metabolite, being extracted by fungal species. More than 200 fungal species are reported to produce carotene [13]. The highest amount of carotene production is reported in class Zygomycetes from order Mucorales. The Mucor, Phycomyces and Blakeslea are Mucorales genus which produce highest amount of carotene. The species of basidiomycetes such as Ustilago, Sclerotinia, Sporidiobolus and Rhodosporidium also produce carotene. The Ascomycetes genus such as, Aspergillus, Penicillium, Aschersonia and Cercospora are also reported to produce efficient amount of carotene [15]. Among fungi pigments like anthraquinone, melanin, naphthaquinones, anthraquinones, dihydroxy naphthalene, flavin, chrysophanol, cynodontin, erythroglaucin, helminthosporin and tritisporin are widely extracted [16].

The marine fungi are also capable of producing variety of pigments [14], those are more or less similar to terrestrial pigments [17]. However, there are some pigments which are only extracted by marine fungi, such as anthracene-glycoside and asperflavin-ribofuranoside, being yellow pigments, are extracted by Microsporum spp [18]. The marine endophytic fungi, such as Halorosellinia [19], Hortaea, Eurotium 
rubrum [20], Phaeotheca,

and

Trimmatostroma are known to produce large amount of pigments. The marine fungi combined with algae and coral enhance the beauty of marine life [14].

\section{Halophilic fungal pigment}

Halophilic fungi are capable of producing numerous extreme extracellular metabolites, which possess great importance in biotechnological applications [21]. Melanin is one of those halophilic metabolites; it was first extracted by black yeast named Hortaea wernecki. This pigment is important in medicinal world, as it showed activity against Salmonella typhi and Vibrio parahaemolyticus. The halophilic pigments are new promising sources of melanin which can be used in pharmaceuticals, and cosmetology [22].

\section{Applications of natural pigments}

The synthetic pigments show a great hazard to health and environment, due to this reason the alternate source of pigments is historically being investigated. The natural pigments show great potential of colors for food, textile, pharmaceuticals and cosmetic industries [23]. The existing microbial pigment extractions process are expensive and require efforts on industrial scale. It is need of time to explore new resources and techniques to extract more eco-friendly, biodegradable colorants [16].

\section{Biotechnological importance of fungal pigments}

Among all microbes, fungi have ability to release pigments in large quantity. They are valuable sources of natural pigments after plants. Fungi release pigment in cheap culture medium, thus making it feasible to use on industrial level. They are eco-friendly way to produce and use bio-colorants [6]. Some of the fungal pigment applications are mentioned in (Table 1).

Table 1. Some representative species of fungi and their biotechnological applications

\begin{tabular}{|c|c|c|c|}
\hline Species & Pigment & Properties & Applications \\
\hline Monascus sp. & $\begin{array}{l}\text { Canthaxanthin, } \\
\text { Ankaflavine, } \\
\text { Monascorubramine } \\
\text { Rubropunctatine }\end{array}$ & $\begin{array}{l}\text { Orange-pink, } \\
\text { Yellow, } \\
\text { Red } \\
\text { Orange }\end{array}$ & $\begin{array}{c}\text { Antioxidants, Anti- } \\
\text { inflammatory, Virucidal, } \\
\text { Antifungal, anti-tumor, anti- } \\
\text { cholestrol activity } \\
{[13,25,26,28]}\end{array}$ \\
\hline $\begin{array}{c}\text { Serratia } \\
\text { marcescens }\end{array}$ & Prodigiosin & Red & $\begin{array}{c}\text { Antibacterial, anticancerous } \\
\text { activity }[37,43]\end{array}$ \\
\hline $\begin{array}{l}\text { Xanthophyllomyces } \\
\text { dendrorhous }\end{array}$ & Astaxanthin & $\begin{array}{l}\text { Yellow, red, } \\
\text { orange }\end{array}$ & Food industry [46] \\
\hline Ashbya gossypii & Riboflavin & Yellow & Food industry [47] \\
\hline $\begin{array}{l}\text { Fusarium } \\
\text { oxysporum }\end{array}$ & Anthraquinone & Blue, violet & Textile industry [51] \\
\hline $\begin{array}{l}\text { Crypotoccus } \\
\text { neoformans, } \\
\text { aspergillus } \\
\text { fumigates }\end{array}$ & Melanin & Brown & $\begin{array}{c}\text { Cosmetics, eye glasses, } \\
\text { sunscreens, sunblocks, } \\
\text { melanoma treatment }[\mathbf{5 5}, \mathbf{5 7}, \\
\mathbf{5 8}]\end{array}$ \\
\hline $\begin{array}{l}\text { Rhodosporidium, } \\
\text { ustilago, sclerotium }\end{array}$ & Carotenoids & Red-orange & $\begin{array}{c}\text { In chemicals, } \\
\text { pharmaceutical, poultry, } \\
\text { food, cosmetics, antioxidant } \\
{[30,15]}\end{array}$ \\
\hline
\end{tabular}




\section{In medicine}

Microorganisms have potential to produce variety of metabolites which show biological and pharmacological activities. Microbial pigments show great antioxidant, anticancer and antimicrobial activities [24]. Amongst microbes, fungi have great potential to release such metabolites which carry biological and pharmacological activities. The fungal genus Monascus are one of those which produce great number of pigments, such as yellow pigment called Ankaflavin, orange-pink pigment named Canthaxanthin, red pigment named Monascorubramin, and orange pigment named Rubropunctatin. All these bio-colorants carry great biotechnological applications such as antitumor, antioxidant and anti-inflammatory properties [25], antifungal and virucidal activity is reported in Penicillium oxalicum [26]. Medicinal significance of some of the important fungal pigments are discussed following.

\section{Antioxidant activity}

The serious diseases such as, cardiovascular, autoimmune disorders, cancer and diabetes are associated with presence of free radicals. The fungal pigments such as carotenoid, violacein and naphthaquinone have been reported to produce efficient amount of antioxidant activity due to the presence of such free radical scavenging compounds [27]. The yellow, orange and red pigments extracted by Monascus species showed great antioxidant and anti-cholesterol activity [28], due to this reason many fermented products of Monascus species are being used on industrial scale. These products carry pigment and are good source of antioxidants [29]. Yeast is good source of carotenoids; extraction of carotenoids is being used as commercial for the sake of biotechnological applications. This fungal pigment contains many medicinally important compounds, in which antioxidants are most valued [30]. The other pigments extracted by filamentous fungi such as melanins, flavins, violacein, indigo and others possess great potential of antioxidant activity, giving coloring and medicinal importance both same time [24].

\section{Antimicrobial activity}

Drug resistance in human disease-causing microorganisms is increasing day by day and multi drug resistance is major problem in red biotechnology. So, it is need of time to look more resources of antimicrobials, in order to overcome drug resistance $[31,32]$. The fungal pigment showed great biotechnological applications which include antimicrobial activity as well. Violacein showed bacteriostatic and bactericidal activity as well as antifungal activity [33]. Violacein also showed antiviral [34], and antiprotozoal activity [35]. Endophytic fungal pigment showed great activity against Klebsiella pneumoniae, Staphylococcus aureus, Salmonella typhi and Vibrio cholera. Their antimicrobial activities were superior to commercially available antibiotic such as streptomycin [36]. A red colored pigment, prodigiosin extracted by Serratia marcescens showed antibacterial activity against grampositive and gram-negative bacteria [37]. Due to great drug resistance developed by these pathogenic microorganisms, new discoveries for such antibiotics are needed constantly. Microbes and their metabolites are good source for such biotechnologically important compounds [38].

\section{Anti-cancerous activity}

Cancer is an uncontrolled growth of abnormal cells and often metastasize to other parts of the body. It is a leading cause of death worldwide. Despite the advancement in the early detection methods and improved therapies. It is still serious health challenge [39]. The microbial pigment reported to possess cell cycle inhibition and induce apoptosis $[40,41]$. Among microbes, fungi possess ability to produce such compounds which show antimicrobial activity, anticancer activity, anti-mutagenic activity and anti- 
obesity properties. Monascus pigment, monascin showed great inhibitory activity against carcinogenesis against mouse skin, Hep G2 and A549 human cancer cell lines. Similarly, Monaphilone A and Monaphilone B, showed anti-proliferative effects against HEp-2 human laryngeal carcinoma cell lines [42]. It was also reported that Anthraquinone from mangrove endophytic fungus Alternaria sp. ZJ9-6B showed anti-cancer activity against human breast cancer cell lines [43]. Prodigiosin, a fungal pigment was tested against 60 different cancer cell lines, and it showed great anticancer activity [44]. All above fungal pigment properties showed that it might be useful and potential therapeutic approach for treatment of cancer.

\section{In food industry}

Natural or synthetic colors are very important in attractive appearance of industrial food making more attractive. The synthetic pigments showed worse effect on health and quality of food which is the main reason that food processers are turning from synthetic to natural colors [45, 46]. Among microorganisms; fungi produce safe and efficient pigments for food processing. Such as red pigment extracted from Monascus $s p$, pink-red pigment from Penicillium oxalicum, astaxanthin from Xanthophyllomyces dendrorhous, $\beta$-carotene from Blakeslea trispora, riboflavin from Ashbya gossypii and ycopene from Erwinia uredovora and Fusarium sporotrichioides are being widely used in food processing industries [47]. Some pigments are used for specific purposes such as carotenoids protect food and act as sunscreen. Canthaxanthin is used in; candy, fish, meat, cheese, snacks, beverages, beer, wine and riboflavin are widely used in ice cream, beverages and instant desserts [48].

\section{For textile}

Textile industry plays a backbone role in economy of any country [49]. In developed countries 1.3 million tons of synthetic dyes and dye precursors are being used per year [45]. In that about 2000000 tons of dyes are wasted as effluents during dyeing and finishing process. The effluents get mixed with waste water treatment process and persist in environment, being nonbiodegradable and show resistance against detergents, water chemicals, soap, temperature, bleach and other remediation [50].

To assess such environmental issues, there is great interest to search for eco-friendly dyes. Natural pigments extracted from microbes are very good source of such eco-friendly dyes [51]. Amongst microorganism; fungal pigment show more feasibility for such applications. Such as Fusarium oxysporum release Anthraquinone which can be used to dye wool fabrics [52], Penicillium minioluteum pigment is being used to dye wet blue goat nappa skin [53], red pigment from Talaromyces verruculosus tone and dye cotton fabric without any cytotoxic effect [50].

Yellow pigment from Thermomyces is evaluated for 3 different fabrics, cotton, silk and wool. The results showed that silk fabric has high affinity for thermomyces pigment as compared with other fabrics [54].

\section{For cosmetics}

The kingdom fungi consist of numerous biologically important active compounds. Many species of basidiomycetes fruiting bodies are being used in traditional medicines and cosmetics. There are plentiful compounds from mushrooms that are being used in nuetraceuticals. The products from such compounds are of many types (such as creams, lotions, applied topically and ointments).

The cosmetic industry is most costly and it is constantly looking for new and natural products. In ancient time, in China and Japan, such compounds that have been used for cosmetics, were reserved for royal families [55]. 
Amongst fungal pigments, melanin show resistance against UV light by absorbing a broad range of electromagnetic spectrum and also protect from photo induced damage [56]. Melanin is produced and extracted by many fungal species such as Cryptococcus neoformans, Colletotrichum lagenarium, Paracoccidioides brasiliensis, Magnaporthe grisea, Sporothrix schenckii and Aspergillus fumigates [57]. Melanin is widely used in cosmetics, eyeglasses, sunscreens, sun blocks, and immobilization of radioactive waste such as uranium. Melanin is being reported in treatment of human metastatic melanoma [58, 59]. Some organic pigments also found in fungi such as carotenoids [60], are widely used in cosmetics especially in sun lotions, anti-aging facial; lycopene is used in lycopene face cream and other products [61]. Conclusion

The kingdom fungi are diverse group of prokaryotes. It produces extracellular metabolites which carry enormous biotechnological applications. The fungal pigment is one of those bio-active compounds. Almost all groups of fungi produce pigments of different colors and characteristics. The most important fungal pigments include carotenoids, melanin, phenazines, violacein, flavins, quinones, indigo etc. These pigments carry antibacterial, antifungal, anti-cancerous and antioxidant potential. Many fungal pigments show a great performance in textile, food and cosmetics industries. The health hazards and environmental concerns of synthetic pigments compel researchers to work and find substitute of such synthetic pigments. To overcome hazards of such issues, extracting fungal pigment and its use could be best solution, as it takes less efforts and cost.

\section{Authors' contributions}

Designed and analysed the data: S Sajid, Advised on research topic: N Akbar, Helped in writing and made critical comments on manuscript: N Akbar, Wrote the manuscript: S Sajid. \& N Akbar.

\section{References}

1. Hari RK, Patel TR \& Martin AM (1994). An overview of pigment production in biological systems: functions, biosynthesis, and applications in food industry. Food Reviews Inter 10(1): 4970.

2. Baurenfeind JC (1981). Natural food colors. In: Baurenfeind, JC, Ed., Careotenoids as colorants and vitamin A precursors, Academic Press, New York, pp 1-45.

3. Delgado-Vargas F, Jiménez AR \& Paredes-López O (2000). Natural pigments: carotenoids, anthocyanins, and betalains-characteristics, biosynthesis, processing and stability. Critical Reviews in Food Sci and Nutrition 40(3): 173-289.

4. Keller NP, Turner G \& Bennett JW (2005). Fungal secondary metabolism from biochemistry to genomics. Nature Reviews Microbiol 3(12): 937.

5. Babitha S, Soccol, CR \& Pandey A (2007). Effect of stress on growth, pigment production and morphology of Monascus sp. in solid cultures. $J$ of Basic Microbiol 47(2): 118-126.

6. Durán N, Teixeira, MF, De Conti R \& Esposito E (2002). Ecological-friendly pigments from fungi. Critical Reviews in Food Sci and Nutrition 42(1): 53-66.

7. Caro Y, Venkatachalam M, Lebeau J, Fouillaud M \& Dufossé L (2017). Pigments and colorants from filamentous fungi. In Fungal metabolites. Springer International Publishing pp 499-568.

8. Gulrajani ML \& Gupta D (1992). Introduction to natural dyes. Indian Institute of Technology, New Delhi.

9. Krishnamurthy KV, Siva R \& Senthil TK (2002). Natural dye-yielding plants of Shervaroy Hills of Eastern Ghats. In Proceedings of National Seminar on the Conservation of the Eastern Ghats, Environment Protection Training and 
Research Institute, Hyderabad pp.151153.

10. Norton RA (1997). Effect of carotenoids on aflatoxin B1 synthesis by Aspergillus flavus. Phytopathol 87(8): 814-821.

11. Aberoumand A (2011). A review article on edible pigments properties and sources as natural biocolorants in foodstuff and food industry. World J Dairy Food Sci 6 (1): 71-78.

12. Babitha S (2009). Microbial pigments. In Biotechnology for agro-industrial residues utilization. Springer Netherlands pp 147-162.

13. Dufossé L, Galaup P, Yaron A, Arad SM, Blanc P, Murthy KNC \& Ravishankar GA (2005). Microorganisms and microalgae as sources of pigments for food use: a scientific oddity or an industrial reality. Trends in Food Sci \& Technol 16(9): 389-406.

14. Dufosse L, Fouillaud M, Caro Y, Mapari SA \& Sutthiwong N (2014). Filamentous fungi are large-scale producers of pigments and colorants for the food industry. Current Opinion in Biotechnol 26: 56-61.

15. Avalos J \& Limón MC (2015). Biological roles of fungal carotenoids. Current Genetics 61(3): 309-324.

16. Babitha S (2009). Microbial pigments. In Biotechnology for agro-industrial residues utilization. Springer Netherlands pp 147-162.

17. Capon RJ, Stewart M, Ratnayake R, Lacey E \& Gill JH (2007). Citromycetins and bilains A-C: new aromatic polyketides and diketopiperazines from Australian marine-derived and terrestrial Penicillium spp. J of Natural Products 70(11): 17461752.

18. Li Y, Li X, Lee U, Kang JS, Choi HD \& Sona BW. (2006). A new radical scavenging anthracene glycoside, asperflavin ribofuranoside and polyketides from a marine isolate of the fungus Microsporum. Chemical and Pharma Bulletin 54(6): 882-883.
19. Li DL, Li XM \& Wang BG (2009). Natural anthraquinone derivatives from a marine mangrove plant-derived endophytic fungus Eurotium rubrum: structural elucidation and DPPH radical scavenging activity. $J$ of Microbiol and Biotechnol 19(7): 675-680.

20. Xia XK, Huang HR, She ZG, Shao CL, Liu F, Cai XL \& Lin YC (2007). 1H and 13C NMR assignments for five anthraquinones from the mangrove endophytic fungus Halorosellinia sp. (No. 1403). Magnetic Resonance in Chem 45(11): 1006-1009.

21. Ali I, Prasongsuk S, Akbar A, Aslam M, Lotrakul P, Punnapayak H \& Rakshit SK. (2016). Hypersaline habitats and halophilic microorganisms. Maejo Inter $J$ of Sci and Technol 10 (3): 330-345.

22. Rani MHS, Ramesh T, Subramanian J \& Kalaiselvam M. (2013). Production and characterization of melanin pigment from halophilic black yeast Hortaea werneckii. Inter J Pharma Res Rev 2(8): 9-17.

23. Chattopadhyay $P$, Chatterjee $S \&$ Sen SK (2008). Biotechnological potential of natural food grade biocolorants. African $J$ of Biotechnol 7(17).

24. Tuli HS, Prachi C, Vikas B \& Anil KS (2015). Microbial pigments as natural color sources: current trends and future perspectives. $J$ of food science and Technol 52(8): 4669-4678.

25. Hsu LC, Hsu YW, Liang YH, Kuo YH \& Pan TM (2011). Anti-tumor and antiinflammatory properties of ankaflavin and monaphilone A from Monascus purpureus NTU 568. J of Agri and Food Chem 59(4): 1124-1130.

26. Andersen DO, Weber ND, Wood SG, Hughes BG, Murray BK \& North JA (1991). In vitro virucidal activity of selected anthraquinones and anthraquinone derivatives. Antiviral Res 16(2): 185-196.

27. Durán M, Ponezi AN, Faljoni-Alario A, Teixeira MF, Justo GZ \& Duran N (2012). Potential applications of violacein: a 
microbial pigment. Medicinal Chem Res 21(7): 1524-1532.

28. Vendruscolo F, Bühler RMM, de Carvalho JC, de Oliveira D, Moritz DE, Schmidell W \& Ninow JL (2016). Monascus: a reality on the production and application of microbial pigments. Appl Biochem and Biotechnol 178(2): 211-223.

29. Yang JH, Tseng YH, Lee YL \& Mau JL (2006). Antioxidant properties of methanolic extracts from monascal rice. LWT-Food Sci and Technol 39(7): 740-747.

30. Mata G, Luis C, Julio CM, Alejandro MZ \& Cristóbal NA (2014). Biotechnological production of carotenoids by yeasts: an overview. Microbial Cell Factories 13(1): 12.

31. Kaye KS \& Kaye D. (2000). Multidrugresistant pathogens: mechanisms of resistance and epidemiology. Current Infectious Disease Reports 2(5): 391-398.

32. Tuli HS, Sandhu SS \& Sharma AK (2014). Pharmacological and therapeutic potential of Cordyceps with special reference to Cordycepin. 3 Biotech 4(1): 1-12.

33. Shirata A, Tsukamoto T, Yasui H, Kato H, Hayasaka S \& Kojima A (1997). Production of bluish-purple pigments by Janthinobacterium lividum isolated from the raw silk and dyeing with them. The $J$ of Sericultural Sci of Japan 66(6): 377385.

34. Andrighetti-Fröhner CR, Antonio RV, Creczynski-Pasa TB, Barardi CRM \& Simões C MO (2003). Cytotoxicity and potential antiviral evaluation of violacein produced by Chromo-bacterium violaceum. Memórias do Instituto Oswaldo Cruz 98(6): 843-848.

35. Costa FTM, Justo G Z, Dura'n N, Nogueira PA \& Lopes SCP (2005). The use of violacein in its free and encapsulated form in polymeric systems against malaria. Brazilian Patent $\mathrm{PIBr}$ 56399.

36. Visalakchi S \& Muthumary J (2009). Antimicrobial activity of the new endophytic Monodictyscastaneae
SVJM139 pigment and its optimization. African $J$ of Microbiol Res 3(9): 550-556.

37. Mekhael R \& Yousif SY (2009). The role of red pigment produced by Serratia marcescens as antibacterial and plasmid curing agent. J Duhok Univ 12(1): 268274.

38. Baltz RH. (2007). Antimicrobials from actinomycetes: back to the future. Microbe-American Society for Microbiol 2(3): 125.

39. Bray F, Jemal A, Grey N, Ferlay J \& Forman D (2012). Global cancer transitions according to the Human Development Index (2008-2030): a population-based study. The Lancet Oncology 13(8): 790-801.

40. Montaner B, Navarro S, Piqué M, Vilaseca M, Martinell M, Giralt E \& Pérez-Tomás R (2000). Prodigiosin from the supernatant of Serratia marcescens induces apoptosis in haematopoietic cancer cell lines. British J of Pharmacol 131(3): 585-593.

41. Pandey R, Chander R \& Sainis KB (2007). Prodigiosins: a novel family of immunosuppressants with anti-cancer activity.

42. Rao N, Prabhu M, Xiao M \& Li WJ. (2017). Fungal and bacterial pigments: Secondary metabolites with wide applications. Frontiers in Microbiol 8: 1113

43. Huang $\mathrm{CH}$, Pan JH, Chen $\mathrm{B}, \mathrm{Yu}, \mathrm{M}$, Huang HB, Zhu X \& Lin YC (2011). Three bianthraquinone derivatives from the mangrove endophytic fungus Alternaria sp. ZJ9-6B from the South China Sea. Marine Drugs 9(5): 832-843.

44. Darshan N \& Manonmani, HK (2015). Prodigiosin and its potential applications. J of Food Sci and Technol 52(9): 5393-5407.

45. Aberoumand A (2011). A review article on edible pigments properties and sources as natural biocolorants in foodstuff and food industry. World $J$ Dairy Food Sci 6: 71-78. 
46. Venil CK, Zakaria ZA \& Ahmad WA (2013). Bacterial pigments and their applications. Process Biochem 48(7): 1065-1079.

47. Dharmaraj S, Ashokkumar B \& Dhevendaran K (2009). Food-grade pigments from Streptomyces sp. isolated from the marine sponge Callyspongiadiffusa. Food Res Inter 42(4): 487-492.

48. Chattopadhyay P, Chatterjee S \& Sen SK. (2008). Biotechnological potential of natural food grade biocolorants. African $J$ of Biotechnol 7(17).

49. Keane J \& Te-Velde DW (2008). The role of textile and clothing industries in growth and development strategies. Overseas Development Institute 7.

50. Ogugbue CJ \& Sawidis T (2011). Bioremediation and detoxification of synthetic waste water containing triarylmethane dyes by Aeromonas hydrophila isolated from industrial effluent. Biotechnology Res Inter.

51. Chadni Z, Rahaman MH, Jerin I, Hoque KMF \& Reza, MA (2017). Extraction and optimisation of red pigment production as secondary metabolites from Talaromycesverruculosus and its potential use in textile industries. Mycology 8(1): 48-57.

52. Nagia FA \& El-Mohamedy RSR (2007). Dyeing of wool with natural anthraquinone dyes from Fusarium oxysporum. Dyes and Pigments 75(3): 550-555.

53. Gupta C \& Aggarwal S (2016). Dyeing wet blue goat nappa skin with a microbial colorant obtained from Penicillium minioluteum. Journal of Cleaner Production 127: 585-590.

54. Poorniammal R, Parthiban M, Gunasekaran S, Murugesan R \& Thilagavathi G (2013). Natural dye production from Thermomyces sp fungi for textile application.

55. Hyde KD, Bahkali AH \& Moslem MA (2010). Fungi-an unusual source for cosmetics. Fungal Diversity 43(1): 1-9.

56. Hill HZ (1992). The function of melanin or six blind people examine an elephant. Bioessays 14(1): 49-56.

57. Langfelder K, Streibel M, Jahn B, Haase G \& Brakhage AA (2003). Biosynthesis of fungal melanins and their importance for human pathogenic fungi. Fungal Genetics and Biol 38(2): 143-158.

58. Plonka PM \& Grabacka M (2006). Melanin synthesis in microorganismsbiotechnological and medical aspects. Acta BiochimicaPolonica 53(3): 429-443.

59. Surwase SN, Jadhav SB, Phugare SS \& Jadhav JP (2013). Optimization of melanin production by Brevundimonas sp. SGJ using response surface methodology. 3 Biotech 3(3): 187-194.

60. Jin JM, Lee J \& Lee YW. (2009). Characterization of carotenoid biosynthetic genes in the ascomycete Gibberellazeae. FEMS Microbiology Lett 302(2): 197-202.

61. Barros L, Ferreira MJ, Queiros B, Ferreira IC \& Baptista P (2007). Total phenols, ascorbic acid, $\beta$-carotene and lycopene in Portuguese wild edible mushrooms and their antioxidant activities. Food Chem 103(2): 413-419. 